\title{
The influence of plate corrugations geometry on plate heat exchanger performance in specified process conditions
}

\author{
O. Arsenyeva ${ }^{\mathrm{a}, *}$, P. Kapustenko ${ }^{\mathrm{b}}$, L. Tovazhnyanskyy $^{\mathrm{b}}$, G. Khavin $^{\mathrm{a}}$ \\ ${ }^{a}$ AO Sodrugestvo-T, 21 Frunze Str, Kharkiv, Ukraine \\ ${ }^{\mathrm{b}}$ Department of Integrated Technologies, Processes and Apparatuses, National Technical University "Kharkiv Polytechnic Institute”, Kharkiv, Ukraine
}

\section{A R T I C L E I N F O}

\section{Article history:}

Received 28 August 2012

Received in revised form

17 December 2012

Accepted 18 December 2012

Available online 16 February 2013

\section{Keywords:}

Plate heat exchanger

Design

Mathematical model

Heat transfer

Plate's geometry

\begin{abstract}
A B S T R A C T
The mathematical model of plate heat exchanger (PHE) is developed using decomposition of the plate on its main corrugated field, which cause major effect on heat transfer, and distribution zone, which influences mostly the hydraulic performance. Model is validated on experimental data for some commercial plates. It is shown, that for specified pressure drop, temperature program and heat load the geometrical parameters of plate and its corrugations, which are enable to make PHE with minimal heat transfer area, can be found. The developed mathematical model can be used for designing of plates with geometry, which is in the best way satisfying process conditions of the certain specific range. The case study for conditions of PHE application in District Heating systems is presented.
\end{abstract}

(ㄷ) 2013 Elsevier Ltd. All rights reserved.

\section{Introduction}

Sustainable development in the process industries requires efficient energy usage and consequent reduction of fuel consumption and greenhouse gas emissions. Efficient heat recuperation is the cornerstone in resolving this problem. When integrating renewables, polygeneration and $\mathrm{CHP}$ units with traditional energy sources in process industries, even new more sophisticated challenges arise, as it is shown by Klemeš et al. [1] and Perry et al. [2]. One of such challenges is a requirement to consider minimal level of temperature differences in heat exchangers of reasonable size, see Varbanov et al. [3]. One of advanced modern types of heat recuperation equipment that can satisfy such conditions is a Plate Heat Exchanger (PHE). Its application not only as a separate item of equipment, but as an elements of a heat exchange networks gives efficient solutions, as shown by Arsenyeva et al. [4]. The design and operation principles of PHEs is well described in literature, see e.g. Wang et al. [5], Shah and Sekulic [6], Tovazhnyansky et al. [7]. The heat transfer processes in this heat exchanger takes place in the channels of complex geometry formed by plates pressed from thin metal. The plates' corrugation form

\footnotetext{
* Corresponding author. Tel.: +380 577202278; fax: +380 577202223.

E-mail addresses: olga.p.arsenyeva@gmail.com, o.arsenyeva@mail.ru, sodrut@ gmail.com (O. Arsenyeva), Petro.Kapustenko@kpi.kharkov.ua (P. Kapustenko).
}

influences strongly on heat and hydraulic behaviour of inter-plate channels. It is the effect similar to that one in enhanced tubes, see e.g. Kukulka et al. [8], Wang et al. [9].

In modern PHEs the plates with straight-line corrugations inclined with the some angle to the plate's vertical axis are generally used (Fig. 1). Such plates, assembled together in one unit, form the channels of criss-cross flow type. These channels have intricate geometry, which is characterised by existence of contact points between the opposite walls in the sites of the corrugations crossing. Geometries of the plates with different corrugation types (sinusoidal and triangular form) are given in Fig. 2. Many authors dealt in their works with investigation of heat transfer and hydraulic resistance in such channels: Focke et al. [10], Muley and Manglik [11], Dović et al. [12], Tovazhnyansky et al. [13], Savostin and Tikhonov [14] and others. The reviews of those works and their results can be found in a book by Wang et al. [5] and papers published by Ayub [15], Dović et al. [12], Khan et al. [16]. The influence of corrugation geometry on exergy loss in PHE channel was experimentally studied by Pandey and Nema [17]. The generalization of the obtained data was performed in form of separate empirical correlations for hydraulic resistance and heat transfer, which are valid for investigated channels only in limited range of hydrodynamic, thermal and geometrical parameters. Martin [18] tried to generalize all the data for hydraulic resistance by the integrated equation on the basis of developed semi-empirical mathematical model. He obtained the relation, which in implicit 


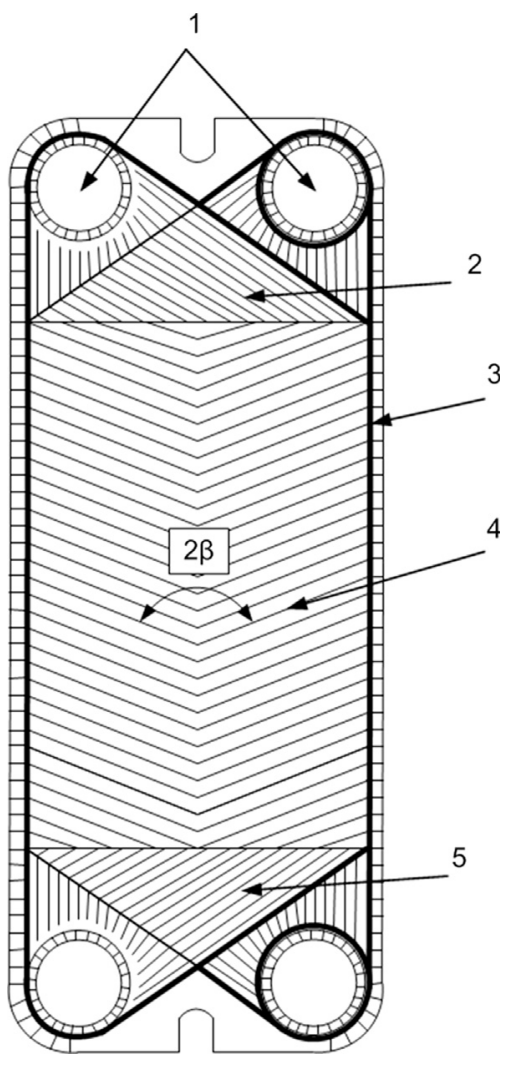

Fig. 1. Schematic drawing of PHE's plate: 1 - the heat carrier inlet and outlet; 2,5 the zones for flow distribution; 3 - the rubber gasket; 4 - the main corrugated field.

form expresses the dependence of hydraulic resistance coefficient from the Reynolds number and geometry parameters of plates' corrugation. But the calculation deviation for this relation from the experimental data of other authors in some cases runs up to $50 \%$ and more. Dović et al. [12] has obtained the similar by accuracy results of their generalizing equation. The low accuracy of generalization in the mentioned works can be explained by attempt to treat together the data obtained for the models of corrugated field with negligible influence of inlet and outlet parts of the channel and data for PHEs assembled with commercial plates.

\section{Mathematical modelling}

\subsection{Prediction of heat transfer and pressure drop}

Let us consider the plate's surface of industrial plate-and-frame PHE, schematically shown in Fig. 1. The working part of that surface, washed by heat exchanging stream flowing inside the channel, consists of the main corrugated field (4) and zones of flow distribution at the inlet (2) and outlet (5). The most part of heat is being transferred on the main corrugated field, which area comes to 80$85 \%$ of the total plate's heat transfer surface area. On the distribution zones considerably less heat is transferred, but their influence on the overall hydraulic resistance of the channel is significant. In these zones the velocities of flow are increasing from the velocity value at the main operating field up to the velocity on the outlet from the channel to the gathering collector of PHE (the same is for inlet from the distributing collector of PHE).

The design of corrugations at distribution zones can considerably vary for different plates, what affects their hydraulic resistance and evenness of flow distribution across the inter-plate channel width. As it can be judged from the data of Tovazhnyansky et al. [13], the share of pressure drop in entrance and exit zones of some PHE channels, formed by commercial plates of chevron type, can reach $50 \%$ and more, especially at lower angles $\beta$ of corrugations inclination to the plate vertical axis.

For the mathematical modelling of thermal and hydraulic performance of PHE the inter-plate channel is considered as consisting of its main corrugated field, which causes the major effect on heat transfer, and distribution zones, which are influencing mostly the hydraulic performance. The empirical equation for calculation of

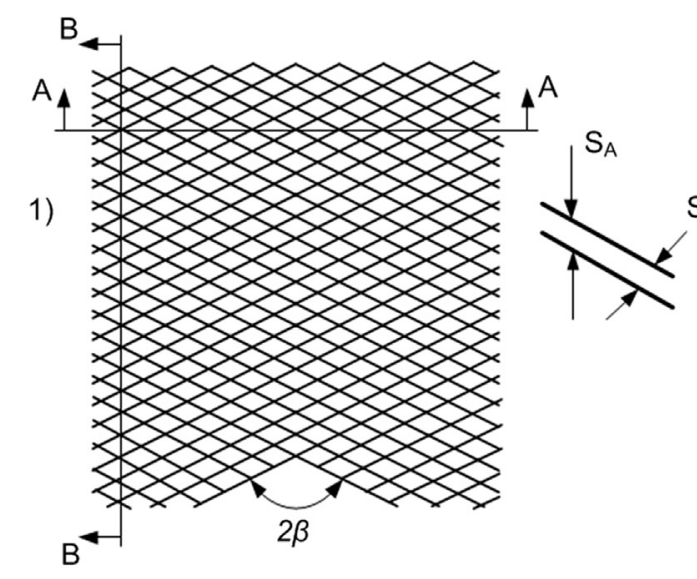

3)

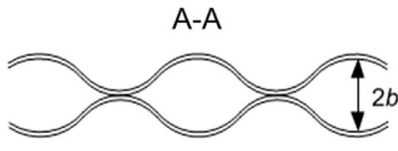

2)

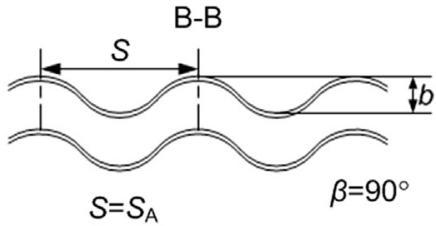

4)
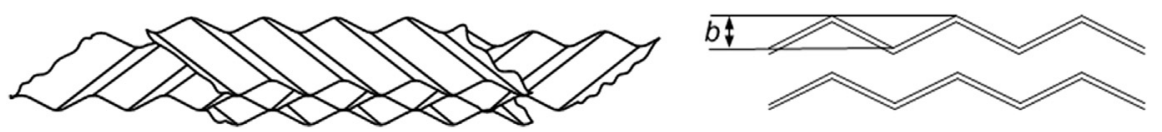

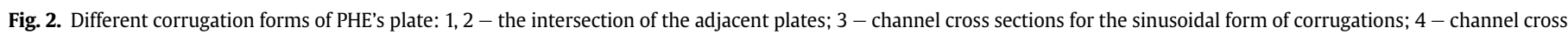
sections for the triangular form of corrugations. 
friction factor $\zeta$ in criss-cross flow channels was reported by Arsenyeva et al. [19]. It enables to predict the friction factors at corrugated field of criss-cross flow channels formed by plates with inclined corrugations in wide range of corrugation parameters. The corrugations inclination angle $\beta$ was varied from $14^{\circ}$ to $72^{\circ}$ and double height to pitch ratio $r$ from 0.52 to 1.02. The range of the Reynolds numbers was from 5 to 25,000 . The difference between sinusoidal and triangular (with rounded edges) shapes of corrugations was practically proved not significant for the coefficient of hydraulic resistance. The equation is as follows:

$$
\begin{aligned}
& \zeta=8 \cdot\left[\left(\frac{12+p_{2}}{\left.\operatorname{Re})^{12}+\frac{1}{(A+B)^{\frac{3}{2}}}\right]^{\frac{1}{12}}}\right.\right. \\
& A=\left[p_{4} \cdot \ln \left(\frac{p_{5}}{\left(\frac{7 \cdot p_{3}}{\operatorname{Re}}\right)^{0.9}+0.27 \cdot 10^{-5}}\right)\right]^{16} ; B=\left(\frac{37530 \cdot p_{1}}{\operatorname{Re}}\right)^{16}
\end{aligned}
$$

where $p_{1}, p_{2}, p_{3}, p_{4}, p_{5}$ are the parameters defined by channel corrugation form.

$$
\begin{aligned}
p_{1}= & \exp (-0.15705 \cdot \beta) \\
p_{2}= & \frac{\pi \cdot \beta \cdot \gamma^{2}}{3} ; \\
p_{3}= & \exp \left(-\pi \cdot \frac{\beta}{180} \cdot \frac{1}{\gamma^{2}}\right) ; \\
p_{4}= & \left(0.061+\left(0.69+\operatorname{tg}\left(\beta \cdot \frac{\pi}{180}\right)\right)^{-2.63}\right) \\
& \cdot\left(1+(1-\gamma) \cdot 0.9 \cdot \beta^{0.01}\right) ; \\
p_{5}= & 1+\frac{\beta}{10}
\end{aligned}
$$

Here $\gamma=2 \cdot b / S$ is the corrugation doubled height to pitch ratio.

The experimental data generalized by Equation (1) were obtained for the models of criss-cross flow channels formed by the plates with the height of corrugations from $1.5 \mathrm{~mm}$ to $10 \mathrm{~mm}$. It confirms that the scale factor in the investigated range of corrugations sizes is accounted by Equation (1) due to its dimensionless form and allows modelling also the influence of inter-plate spacing on the PHE hydraulic performance. To account for pressure losses in the distribution zones ( 2 and 5 in Fig. 1 ) of the inter-plate channel formed by commercial plates, it has been introduced the coefficient of local hydraulic resistance in those zones $\zeta_{\mathrm{Dz}}$, assuming that these coefficients for the inlet and outlet zones are equal. The average velocity of stream at the main corrugated field $w$ is assumed as characteristic velocity in determining these coefficients. The total pressure loss in the PHE channel can be calculated as follows:

$\Delta p=\zeta \cdot \frac{L_{F}}{d_{e}} \cdot \frac{\rho \cdot w^{2}}{2}+\zeta_{\mathrm{DZ}} \cdot \rho \cdot w^{2}$

where $\rho$ is the fluid density, $\mathrm{kg} / \mathrm{m}^{3} ; L_{F}$ is the length of corrugated field, $\mathrm{m} ; d_{e}=2 \cdot b$ is the equivalent diameter of the channel, $\mathrm{m}$.

In paper [13] it was observed, that for the plates investigated there with different forms of corrugations, but with similar constructed distribution zones, the coefficients $\zeta_{\mathrm{DZ}}$ are close in values. For different plates there were obtained the values of such coefficients from 25 to 110 . For four out of six investigated plates the average value was 27.25 . For those plates the ratio of the length of corrugated field $L_{F}$ to effective plate length $L_{\mathrm{EF}}$ used in the $\zeta_{\mathrm{DZ}}$ calculations, was equal to 0.72 . The value of coefficient $\zeta_{\mathrm{DZ}}$ from paper [13] should be divided by this ratio to use it in Equation (3). It gives
$\zeta_{\mathrm{DZ}}=38$. This value is used in our model, considering the construction of distribution zones in these four plates as more preferable for the reproduction in process of new plate development. The particular design of distribution zones is a complex problem which is not considered in this paper. It is assumed that performance of these zones is the same as for better distribution zones on commercial plates examined in papers [11] and [13].

To validate the model of hydraulic resistance we have compared the results of calculations by Equations (1)-(3) with experimental data for commercial plates published by Muley and Manglik [11]. All corrugations parameters are taken from paper [11] and the length of the main corrugated field from drawing presented there is $L_{F}=278 \mathrm{~mm}$. The maximal deviation of calculated results from experimental data not exceeded $15 \%$ (see Fig. 3, filled squares and circles) with mean square error $\pm 5 \%$. Counting that the maximal error reported in paper [13] not exceeded $15 \%$ for four other different commercial plates, the model can be used for estimation of the hydraulic performance for PHEs assembled from plates with different geometrical characteristics.

More detailed examination of the graph in Fig. 3 leads to conclusion about the influence of the Reynolds number on the $\zeta_{\mathrm{DZ}}$ value. The flow at the distribution zone of the channel has a complex character, but the existence of contact points between adjacent plates makes possible the assumption that the influence of the Reynolds number on hydraulic resistance in this zone is similar to that one on a main corrugated field, especially at high $\beta$ values approximated by Eq. (1). So, $\beta$ equal to $65^{\circ}$ was taken for the calculation of the correction factor. The closest match of calculated and experimental pressure losses in Fig. 3 is at $R e=2700$. Then the correction factor for $\zeta_{\mathrm{DZ}}$ may be introduced as the ratio of $\zeta_{65}(R e)$, calculated by Eq. (1) with $\beta=65^{\circ}$ at examined $R e$ and all other parameters like for the main corrugated field, to that value at $\operatorname{Re}=2700$ :

$\zeta_{\mathrm{DZ}}=38 \cdot \frac{\zeta_{65}(R e)}{\zeta_{65}(2700)}$

The comparison of calculations by Eq. (3) with $\zeta_{\mathrm{DZ}}$ determined from Eq. (4) presented in Fig. 3 as hollow squares and circles. The discrepancies are not more than $3 \%$, that is well within the experimental error reported in cited paper [11].

For calculation of film heat transfer coefficients in PHE channels the analogy between heat and momentum transfer can be used, as it is demonstrated by Kapustenko et al. [20]. Based on modified Reynolds analogy the following equation was proposed:

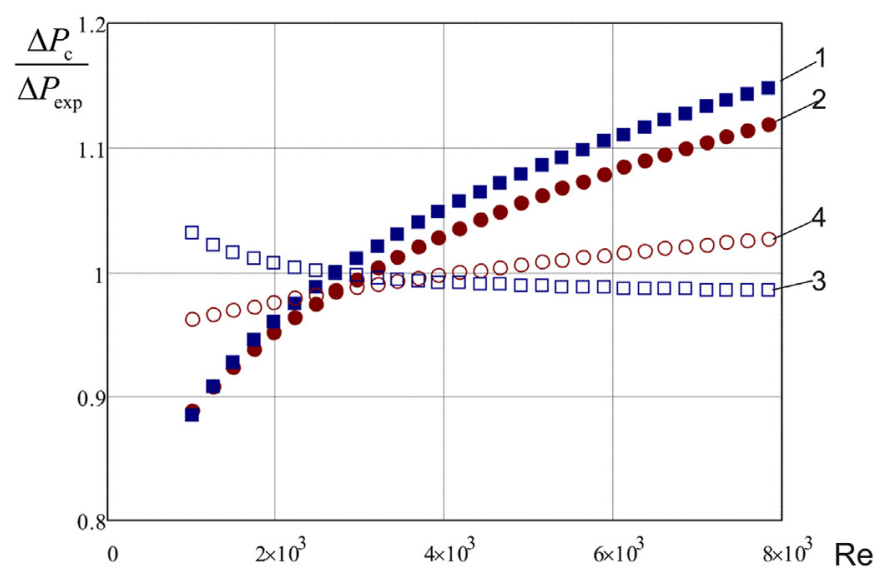

Fig. 3. The comparison of calculated pressure losses with experimental data in paper [11] for PHEs assembled from commercial plates: $1-\beta=30^{\circ} ; 2-\beta=60^{\circ}$ (for $\zeta_{\mathrm{DZ}}=38$ ); $3-\beta=30^{\circ} ; 4-\beta=60^{\circ}$ (for $\zeta_{\mathrm{DZ}}$ calculated by Eq. (4)). 
$N u=0.065 \cdot \operatorname{Re}^{6 / 7} \cdot\left(\psi \cdot \zeta / F_{x}\right)^{3 / 7} \cdot \operatorname{Pr}^{0.4} \cdot\left(\mu / \mu_{w}\right)^{0.14}$

Here $\mu$ and $\mu_{w}$ are the dynamic viscosities at stream and at wall temperatures, Pa s; $N u=h \cdot d_{e} / \lambda$ is the Nusselt number; $\lambda$ is the thermal conductivity of the stream, $\mathrm{W} /(\mathrm{m} \mathrm{K}) ; d_{e}$ is the equivalent diameter of channel, $\mathrm{m} ; h$ is the film heat transfer coefficient, $\mathrm{W} /$ $\left(\mathrm{m}^{2} \mathrm{~K}\right) ; \operatorname{Pr}$ is the Prandtl number; $R e=w \cdot d_{e} \cdot \rho / \mu$ is the Reynolds number; $w$ is the stream velocity in the channel, $\mathrm{m} / \mathrm{s}$; $\zeta$ is the friction factor accounting for total pressure losses in the channel, calculated by Equation (1); $\psi$ is the share of pressure loss due to friction on the wall in total loss of pressure.

The value of $\psi$ can be estimated by the following Equation:

$A_{1}=380 /[\operatorname{tg}(\beta)]^{1.75} ;$ at $\operatorname{Re}>A_{1} \psi=\left(\operatorname{Re} / A_{1}\right)^{-0.15 \cdot \sin (\beta)}$; at

$\operatorname{Re} \leq A_{1} \psi=1$

The comparison with data available in literature has shown that the error of heat transfer prediction calculated by Equation (4) is not larger than $15 \%$ in the following range of corrugations parameters: $\beta$ from $14^{\circ}$ to $65^{\circ} ; \gamma$ from 0.5 to $1.5 ; F_{x}$ from 1.14 to 1.5 . This is confirmed for the Reynolds numbers from 100 to 25,000 for both shapes of individual corrugations: sinusoidal and triangular with rounded edges. The comparison with data for some commercial plates also gave good results.

The presented mathematical model enables to predict the friction factor and film heat transfer coefficients in PHE channels basing on a data of their corrugations' geometrical parameters, such as the corrugation angle $\beta$, the aspect ratio $\gamma$ and the coefficient of surface area enlargement $F_{x}$. It enables to investigate the influence of these parameters, as well as corrugations' height (equal to inter-plate spacing) and plate's size on the PHE performance in specific process conditions.

\subsection{The best geometry of plate for specific process}

Performing design of heat exchanger for cooling of process fluid an engineer must strictly satisfy thermal and hydraulic conditions on the process side. The initial temperature of cooling water as well as its quality also cannot be influenced by the designer. These parameters are the same for any type of heat exchanger which can be utilized on this process position - tubular, different kinds of PHEs or others. In a general case the flow rate and hence the outlet temperature of cooling water can be varied, but it is also frequently strictly specified due to constraints on a whole cooling system of the enterprise. In case of recuperative PHE, which exchanging heat between two process streams, as a rule, the conditions on both sides cannot be changed. Only internal parameters of PHE construction can be varied, like the number, size and corrugation pattern of plates, the number of streams passes. It can lead to different channel geometries, flow velocities and wall temperatures inside the heat exchanger.

Let's assume that the following heat transfer process conditions are specified:

$t_{11}, t_{12}$ are the inlet and outlet temperatures of the hot stream, ${ }^{\circ} \mathrm{C}$;

$t_{21}, t_{22}$ are the inlet and outlet temperatures of the cold stream, ${ }^{\circ} \mathrm{C}$;

$q_{m 1}, q_{m 2}$ are the mass flow rates of the hot and cold streams, respectively, $\mathrm{kg} / \mathrm{s}$;

$\Delta P_{1}^{0}, \Delta P_{2}^{0}$ are the allowable pressure drops for the hot and cold streams, respectively, Pa.
The heat load of heat exchanger must be not less than the specified:

$\Phi=\left(t_{11}-t_{12}\right) \cdot c_{p 1} \cdot q_{m 1}=\left(t_{22}-t_{21}\right) \cdot c_{p 2} \cdot q_{m 2}$

where $c_{p 1}$ and $c_{p 2}$ are the specific heat capacities of the hot and cold fluids, $\mathrm{J} /(\mathrm{kg} \mathrm{K}) ; \rho_{1}$ and $\rho_{2}$ are the fluids densities, $\mathrm{kg} / \mathrm{m}^{3}$.

The pressure losses in heat exchanger must be not bigger than allowable for each stream. In PHE the numbers of channels for two heat exchanging streams differ not more than on one. It permits to satisfy completely the pressure drop condition only for one stream, but for another one the pressure drop will be less than allowable. Let's assume that it is the hot stream (if it is opposite, the procedure is analogues).

When designing PHE the task is to obtain the heat exchanger with minimal heat transfer area satisfying required process conditions. From Equation (3) it is fairly clear that the best result can be obtained with one pass counter current PHE, as for the multiple passes it is increases the number of distribution zones through which the stream flows. Also the additional pressure losses are added owing to the turning flow in collectors between passes. The special case when unsymmetrical passes number may be necessary, as e.g. one example in paper [4], is not considered here. Let's assume that to satisfy process conditions for the given geometry of corrugations on the main heat transfer field of the plate the plate length should be changed. It is similar to the design approach proposed by Picon-Nunez et al. [21] in graphical form.

When pressure drop condition for the hot stream is satisfied completely, from the Eq. (3) one can get:

$\frac{L_{F}}{b}=\frac{4}{\zeta_{1}\left(w_{1}\right)} \cdot\left(\frac{\Delta P_{1}^{0}}{\rho_{1} \cdot w_{1}}-\zeta_{\mathrm{DZ}}\right)$

where $w_{1}$ is the flow velocity of hot stream in PHE channels; $\zeta_{\mathrm{DZ}}$ is the coefficient calculated by Eq. (4) and $\zeta_{1}\left(w_{1}\right)$ by Eq. (1) at this flow velocity.

It is required by the process conditions that the number of heat transfer units for the hot stream in the heat exchanger must be not less than

$\mathrm{NTU}^{0}=\frac{\left(t_{11}-t_{12}\right)}{\Delta t_{\ln }}$

where $\Delta t_{\ln }$ is the mean logarithmic temperature difference

$\Delta t_{\ln }=\frac{\left(t_{11}-t_{22}\right)-\left(t_{12}-t_{21}\right)}{\ln \left(\frac{t_{11}-t_{22}}{t_{12}-t_{21}}\right)}$

On the other hand, the number of heat transfer units, which can be obtained in one PHE channel:

$\mathrm{NTU}=\frac{2 \cdot U \cdot F_{\mathrm{pl}}}{c_{p 1} \cdot w_{1} \cdot \rho_{1} \cdot f_{\mathrm{ch}}}$

here $U$ is the overall heat transfer coefficient, $\mathrm{W} /\left(\mathrm{m}^{2} \mathrm{~K}\right) ; f_{\mathrm{ch}}=W b$ is the channel cross section area, $\mathrm{m}^{2} ; W$ is the width of the channel, $\mathrm{m} ; F_{\mathrm{pl}}$ is the heat transfer area of one plate, $\mathrm{m}^{2}$.

Estimating approximately, that the heat transfer area of distribution zones is about $15 \%$ of the total plate heat transfer area, it is obtained:

$F_{\mathrm{pl}}=L_{F} \cdot W \cdot F_{X} / 0.85$

where $F_{X}$ is the ratio of developed area to projected area. 
For PHE, which exactly satisfies the process conditions, NTU calculated by Eq. (11) should be equal to that required by the process (Eq. (9)) and we can estimate the plate length to fulfil this:

$\frac{L_{F}}{b}=\frac{\mathrm{NTU}^{0} \cdot 0.85 \cdot c_{p 1} \cdot w_{1} \cdot \rho_{1}}{2 \cdot U \cdot F_{X}}$

When both conditions, for the heat load and pressure drop of the hot stream, are satisfied the Equations (8) and (13) form a system of two algebraic Equations with two unknown variables $L_{F}$ and $w_{1}$. Excluding $L_{F} / b$, one equation with one unknown is obtained as follows:

$w_{1}=\sqrt{\frac{\Delta P_{1}^{0}}{\rho_{1}} \cdot \frac{1}{\zeta_{\mathrm{DZ}}\left(w_{1}\right)+\zeta_{1}\left(w_{1}\right) \cdot \frac{\mathrm{NTU}^{0} \cdot 0.85 \cdot c_{p 1} \cdot w_{1} \cdot \rho_{1}}{8 \cdot U\left(w_{1}\right) \cdot F_{X}}}}$

For the given geometrical parameters of corrugations $\left(\beta, r, F_{X}\right)$ the friction factor $\zeta_{1}\left(w_{1}\right)$ depends only on the velocity $w_{1}$ and can be determined by nonlinear Equation (1). The same is valid for $\zeta_{\mathrm{DZ}}$ $\left(w_{1}\right)$, which is determined by Eq. (4) and Eq. (1). The overall heat transfer coefficient can be expressed as:

$\frac{1}{U}=\frac{1}{h_{1}}+\frac{1}{h_{2}}+\frac{\delta_{w}}{\lambda_{w}}+R_{\mathrm{foul}}$

where $\delta_{w}$ is the wall thickness, $\mathrm{m} ; \lambda_{w}$ is the thermal conductivity of the wall, $\mathrm{W} /(\mathrm{m} \mathrm{K}) ; R_{\text {foul }}$ - is the thermal resistance of fouling $\left(\mathrm{m}^{2} \mathrm{~K}\right) / \mathrm{W} ; h_{1}$ and $h_{2}$ are the film heat transfer coefficients for the hot and cold stream, respectively, $\mathrm{W} /\left(\mathrm{m}^{2} \mathrm{~K}\right)$.

The film heat transfer coefficients are determined by Equations (5) and (6), and for known physical properties of streams and channels' geometry they are depend only on the flow velocities in PHE channels. Using the intrinsic feature of PHE it can be assumed that the numbers of channels for two streams are equal. The geometry of the channels is also the same. So flow velocity in channels of the cold stream can be expressed via flow velocity in channels of the hot stream (and vice versa):

$w_{2}=w_{1} \cdot \frac{q_{m 2} \cdot \rho_{1}}{q_{m 1} \cdot \rho_{2}}$

The thermal resistance of fouling in PHEs is much lower than in shell and tubes heat exchangers (see Refs. [5,22]). As shown by Gogenko et al. [22] for some fouling mechanisms, it depends on the flow velocity. In the present paper this phenomena is not considered and for clarity it is assumed that $R_{\mathrm{foul}}=0$.

Based on above it can be concluded that for the given geometrical parameters of corrugations $\left(\beta, r, F_{x}\right)$ the overall heat transfer coefficient depends only on flow velocity $w_{1}$ and can be calculated using Equations (5), (6), (15) and (16).

The nonlinear algebraic Equation (14), accompanied by Equations (1), (2), (4)-(6), (15), (16) cannot be solved analytically, but its solution is easily obtained numerically on a computer using iterative procedure. The solution gives the value of flow velocity $w_{1}$ in channels. After that the corresponding plate length, at which specified heat transfer load and pressure drop of one stream are exactly satisfied, is calculated from Equation (8). For the specified process conditions and fixed corrugations parameters, due to full utilization of pressure drop, the maximal overall heat transfer coefficients and minimal heat transfer area can be achieved. It enables to determine the influence of plate corrugations geometrical parameters on PHE's ability to satisfy the specific process conditions with minimal heat transfer area. The example of such analysis is presented in the following case study.

\section{Case study}

As an example the conditions of PHE application in District Heating (DH) system were examined. The heat exchanger heats the radiator water in the house internal circuit from $t_{21}=70^{\circ} \mathrm{C}$ to $t_{22}=95^{\circ} \mathrm{C}$ using the DH water, which comes with $t_{11}$ temperature $\left(t_{11}=120^{\circ} \mathrm{C}\right)$ and is discharged with temperature $t_{12}=75^{\circ} \mathrm{C}$. The allowable pressure losses are $\Delta_{1}^{0}=20 \mathrm{kPa}, \Delta_{2}^{0}=70 \mathrm{kPa}$. Two cases with different heat load are considered: $\Phi_{1}=600 \mathrm{~kW}$, what is typical for medium size apartment block, $\Phi_{2}=3000 \mathrm{~kW}$, as for big apartment house or complex of such houses. The flow rates of the streams are readily calculated from heat balance given by Eq. (7).

To study the influence of plate geometry on PHE's ability to satisfy this specific process conditions the model presented above was used. It enables to calculate the plate length at which all the process parameters will be satisfied completely. This length considerably varies with changing of the corrugations geometry, as can be seen from the graphs in Fig. 4. The corresponding flow velocity in channels, overall heat transfer coefficient and required heat transfer area are depended on these parameters too. Analysing graphs on Figs. 4-6, one can conclude, that the required heat transfer area $F_{a}$ decreases with rising of the corrugations inclination angle $\beta$ and with descent of the plate spacing $b$. The minimal $F_{a}$ values can be observed at the edge of model application limits. For examined two cases the minimal heat transfer area is $F_{a 1}=6.06 \mathrm{~m}^{2}$ and $F_{a 2}=30.28 \mathrm{~m}^{2}$ at $\beta=65^{\circ}$ and $b=1.5 \mathrm{~mm}$ (see Fig. 4). At the same time the length of the required plates' corrugated field $L_{F}$ also decreases significantly down to $300 \mathrm{~mm}$. To organize equal distribution of flow across the width of inter-plate channels it is preferable to have bigger ratio of plate length to its width or $L_{F} / b$. In majority of commercially produced plates it varies from 1.5 to 2.5. To estimate the heat transfer area of the plate let's take $L_{F} / b=2$. Then the heat transfer area of one plate:

$F_{\mathrm{pl}}=L_{F}^{2} \cdot F_{X} /(2 \cdot 0.85)$

The heat transfer area of the plate with $L_{F}=300 \mathrm{~mm}$ should be $F_{\mathrm{pl} 1}=0.066 \mathrm{~m}^{2}$ and PHE for the first case will require 92 such heat transfer plates. These plates can be used efficiently for heat loads less than $600 \mathrm{~kW}$, with less number of plates in PHE. The number of heat transfer plates in one PHE is restricted mainly because of the limited diameter of the inlet and outlet ports, what causes the excessive flow velocities in ports and unnecessary pressure losses there. Let's assume that the maximum number of plates in one PHE that should be designed for the regarded process conditions is 120 .

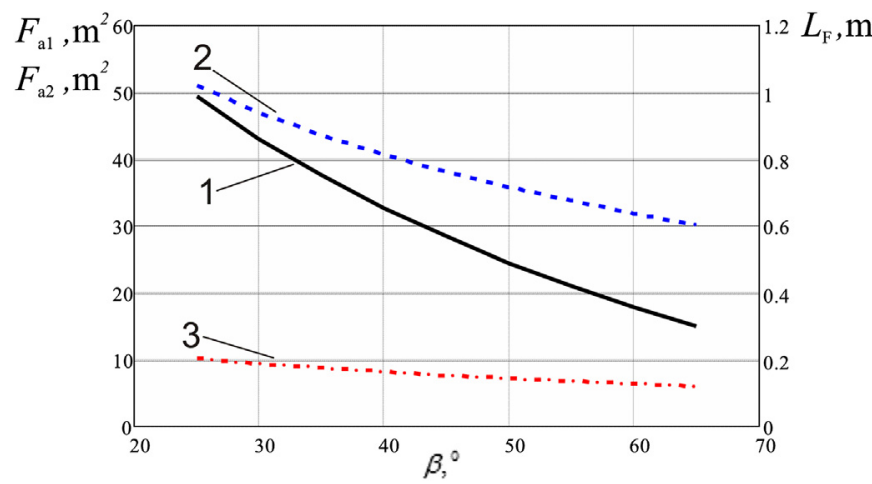

Fig. 4. The dependence of the required plate length $L_{F}$ and PHE's heat transfer area on the corrugations angle $\beta$ with $b=1.5 \mathrm{~mm}$. $1-L_{F} ; 2-F_{a 2}$ for $\Phi_{2}=3000 \mathrm{~kW} ; 3-F_{a 1}$ for $\Phi_{1}=600 \mathrm{~kW}$. 


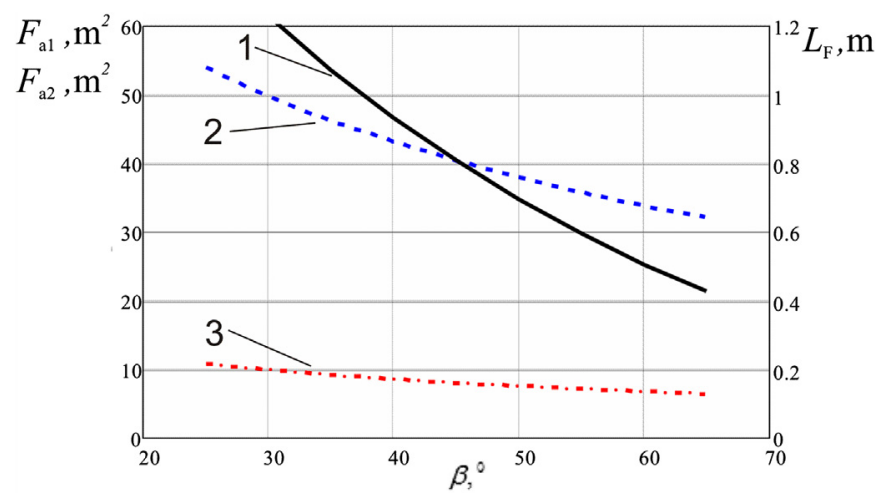

Fig. 5. The dependence of the required plate length $L_{F}$ and PHE's heat transfer area on the corrugations angle $\beta$ with $b=2 \mathrm{~mm}$. $1-L_{F} ; 2-F_{a 2}$ for $\Phi_{2}=3000 \mathrm{~kW} ; 3-F_{a 1}$ for $\Phi_{1}=600 \mathrm{~kW}$.

For the first case with the heat load equal to $600 \mathrm{~kW}$ the obtained 92 plates are inside this limit, but for the $3000 \mathrm{~kW}$ it is needed to use 460 plates. This amount cannot be handled in one frame and therefore it should be considered to apply longer plate. For this purpose the plate with bigger length $L_{F}$ must be taken. To do that the corrugations angle $\beta$ can be changed keeping the plate spacing $b$ at value $1.5 \mathrm{~mm}$, as follows from the graph in Fig. 4. For $\beta=37^{\circ}$ the length of plate is $L_{F}=710 \mathrm{~mm}$ and its heat transfer area $F_{\mathrm{pl} 1}=0.37 \mathrm{~m}^{2}$. The required total heat transfer area of PHE equals to $F_{a 2}=42.4 \mathrm{~m}^{2}$ and this unit can be assembled from 115 plates. It is within imposed limit for the maximum number of plates, but $F_{a 2}$ is on $40 \%$ larger than previously found minimal area, which was $30.28 \mathrm{~m}^{2}$.

Another option is to increase the required plate length by taking wider plate spacing, as can be judged from the graph in Fig. 5. For the plate with $2 \mathrm{~mm}$ spacing the minimal heat transfer areas for both cases under consideration are $F_{a 1}=6.43 \mathrm{~m}^{2}$ and $F_{a 2}=32.15 \mathrm{~m}^{2}$ at $\beta=65^{\circ}$, this means $6 \%$ increase in comparison with the same values at $1.5 \mathrm{~mm}$ spacing. At the same time for $\beta=50^{\circ}$ the length of the plate is $L_{F}=700 \mathrm{~mm}$ and its heat transfer area equals $F_{\mathrm{pl} 1}=0.35 \mathrm{~m}^{2}$. The required total PHE heat transfer area is $F_{a 2}=38 \mathrm{~m}^{2}$ (25\% more than minimal for $\left.b=1.5 \mathrm{~mm}\right)$ and the unit can be assembled from 109 plates.

If further increase the plate spacing to $2.5 \mathrm{~mm}$ (see Fig. 6), the minimal heat transfer areas for both cases under consideration are $F_{a 1}=6.74 \mathrm{~m}^{2}$ and $F_{a 2}=33.72 \mathrm{~m}^{2}$ at $\beta=65^{\circ}$, or $11 \%$ more than these values at $1.5 \mathrm{~mm}$ spacing. With this spacing we can find the plate

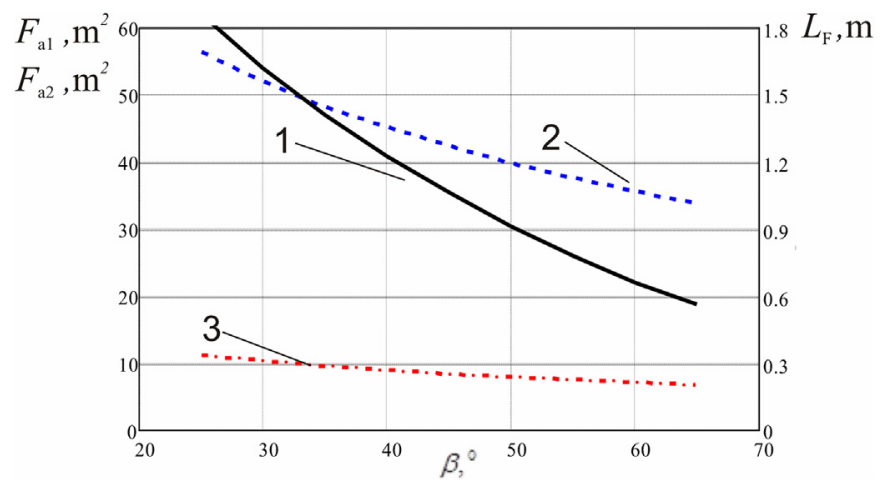

Fig. 6. The dependence of the required plate length $L_{F}$ and PHE's heat transfer area on the corrugations angle $\beta$ with $b=2.5 \mathrm{~mm} .1-L_{F} ; 2-F_{a 2}$ for $\Phi_{2}=3000 \mathrm{~kW} ; 3-F_{a 1}$ for $\Phi_{1}=600 \mathrm{~kW}$. length $L_{F}=640 \mathrm{~mm}$ and its heat transfer area $F_{\mathrm{pl} 1}=0.30 \mathrm{~m}^{2}$ at $\beta=61^{\circ}$. The heat transfer area here is $35.1 \mathrm{~m}^{2}$ and it consists from 117 plates, what is $16 \%$ greater than minimal at $b=1.5 \mathrm{~mm}$. Another option is the plate with $L_{F}=910 \mathrm{~mm}$ and the heat transfer area equal to $0.61 \mathrm{~m}^{2}$ at $\beta=50^{\circ}$, but it requires $F_{a 2}=39.6 \mathrm{~m}^{2}$ with 65 plates ( $31 \%$ larger than $30.28 \mathrm{~m}^{2}$ ).

The presented case study shows, that the geometry of corrugations, as well as plate length, is considerably influencing the performance of PHE. To satisfy process conditions with minimal heat transfer area the plates with different sizes and various geometrical parameters are needed. For the smaller heat transfer load (in our case less than $600 \mathrm{~kW}$ ) the plates with smaller spacing and $\beta=65^{\circ}$ give the highest overall heat transfer coefficient and the smallest heat transfer area in one PHE. To accommodate bigger heat loads in one PHE it is necessary to increase the plate length and hence the heat transfer area of one plate. It is possible by decreasing the angle $\beta$ or by increasing plate spacing $b$ under the consideration of the allowable pressure drop full utilisation with the exact satisfaction of the heat load. The second method is preferable, as gives less decrease in overall heat transfer coefficient and smaller heat transfer area. For specified process conditions the corrugation geometry and plate's size, which give the minimal PHE heat transfer area, can be found.

\section{Conclusions}

The presented mathematical model enables to predict the influence of the plate corrugation parameters on PHE performance. For the specified process conditions (pressure drop, temperature program, heat load and streams physical properties) the geometrical parameters of plate and its corrugations, which enable to make PHE with minimal heat transfer area, can be found. It requires to develop optimization algorithm and software, which is the subject of further research.

For different heat transfer process conditions the best values of plate geometrical parameters significantly vary. It requires to design and manufacture the plates of different sizes and geometrical form of corrugations, which can better satisfy certain ranges of applications. In commercial PHEs the variety of corrugation inclination angles is achieved by combination of two plates with different corrugation angles in one frame. The number of plate sizes and plates with different spacing is limited. All of this leads to situation that optimal corrugation parameters cannot be reached with already available types of plates. But having the optimal plate geometry for the given process, this data can be used as a reference point of what can be achieved with PHE on certain position. Besides, the developed mathematical model can be used for designing of new plates with the geometry, which in the best way satisfies the process conditions or some range of them.

\section{Acknowledgements}

The support of EC Project INTHEAT (contract No FP7-SME-2010$1-262205)$ is sincerely acknowledged.

\section{References}

[1] Klemeš J, Friedler F, Bulatov I, Varbanov P. Sustainability in the process industry. Integration and optimization. New York, USA: The McGraw-Hill Co-s. Inc; 2010.

[2] Perry S, Klemes J, Bulatov I. Integrating waste and renewable energy to reduce the carbon footprint of locally integrated energy sectors. Energy 2008;33. 1489-97.

[3] Varbanov PS, Fodor Z, Klemeš JJ. Total site targeting with process specific minimum temperature difference ( $\Delta$ Tmin). Energy 2012;44:20-8. 
[4] Arsenyeva O, Tovazhnyansky L, Kapustenko P, Khavin G. Optimal design of plate-and-frame heat exchangers for efficient heat recovery in process industries. Energy 2011;36:4588-98.

[5] Wang L, Sunden B, Manglik RM, PHEs. Design, applications and performance. Southhampton, UK: WIT Press; 2007.

[6] Shah RK, Sekulić DP. Fundamentals of heat exchanger design. New York: Wiley and Sons; 2003.

[7] Tovazshnyansky LL, Kapustenko PO, Khavin GL, Arsenyeva OP. PHEs in industry. Kharkiv: NTU KhPI; 2004.

[8] Kukulka DJ, Smith R, Fuller KG. Development and evaluation of enhanced heat transfer tubes. Applied Thermal Engineering 2011;31:2141-5.

[9] Wang QW, Lin M, Zeng M. Effect of lateral fin profiles on turbulent flow and heat transfer performance of internally finned tubes. Applied Thermal Engineering 2009;29:3006-13.

[10] Focke WW, Zacharadies J, Olivier I. The effect of the corrugation inclination angle on the thermohydraulic performance of plate heat exchangers. International Journal of Heat and Mass Transfer 1985;28:1469-79.

[11] Muley A, Manglik RM. Experimental study of turbulent flow heat transfer and pressure drop in a plate heat exchanger with chevron plates. ASME Journal of Heat Transfer 1999;121:110-7.

[12] Dović D, Palm B, Švaić S. Generalized correlations for predicting heat transfer and pressure drop in plate heat exchanger channels of arbitrary geometry. International Journal of Heat and Mass Transfer 2009;52:4553-63.

[13] Tovazhnyansky LL, Kapustenko PA, Tsibulnic VA. Heat transfer and hydraulic resistance in channels of plate heat exchangers. Energetika 1980;9: $123-5$.

[14] Savostin AF, Tikhonov AM. Investigation of the characteristics of plate-type heating surfaces. Thermal Engineering 1970;17(9):113-7.

[15] Ayub ZH. Plate heat exchanger literature survey and new heat transfer and pressure drop correlations for refrigerant evaporators. Heat Transfer Engineering 2003;24(5):3-16.

[16] Khan TS, Khan MS, Chyu M-C, Ayub ZH. Experimental investigation of single phase convective heat transfer coefficient in a corrugated plate hea exchanger for multiple plate configurations. Applied Thermal Engineering 2010;30:1058-65.

[17] Pandey SD, Nema VK. An experimental investigation of exergy loss reduction in corrugated plate heat exchanger. Energy 2011;36:2997-3001.

[18] Martin H. Theoretical approach to predict the performance of chevrontype plate heat exchangers. Chemical Engineering and Processing 1996; 35:301-10.

[19] Arsenyeva O, Tovazhnyansky L, Kapustenko P, Khavin G. The generalized correlation for friction factor in crisscross flow channels of plate heat exchangers. Chemical Engineering Transactions 2011;25:399-404.

[20] Kapustenko P, Arsenyeva O, Dolgonosova O. The heat and momentum transfers relation in channels of plate heat exchangers. Chemical Engineering Transactions 2011;25:357-62.

[21] Picon-Nunez M, Polley GT, Jantes-Jaramillo D. Alternative design approach for plate and frame heat exchangers using parameter plots. Heat Transfer Engineering 2010;31(9):742-9.
[22] Gogenko AL, Anipko OB, Arsenyeva OP, Kapustenko PO. Accounting for fouling in plate heat exchanger design. Chemical Engineering Transactions 2007;12: 207-13.

\section{Nomenclature}

$b$ : corrugation height, $\mathrm{m}$

$c_{p}$ : specific heat capacity of the fluid, $\mathrm{J} /(\mathrm{kg} \mathrm{K})$

$d_{e}$ : equivalent diameter of the channel, $\mathrm{m} ; d_{e}=2 \cdot b$

$F_{x}$ : coefficient of surface area enlargement

$F_{p l}$ : heat transfer area of one plate, $\mathrm{m}^{2}$

$f_{\text {ch }}$ : channel cross section area, $\mathrm{m}^{2} ; f_{\mathrm{ch}}=W b$

$q_{m}$ : mass flow rate, $\mathrm{kg} / \mathrm{s}$

$h$ : film heat transfer coefficient, $\mathrm{W} /\left(\mathrm{m}^{2} \mathrm{~K}\right)$

$L_{F}$ : the length of corrugated field, $m$

$L_{E F}$ : effective plate length, $\mathrm{m}$

$\triangle P^{0}$ : allowable pressure drop, $\mathrm{Pa}$

$R_{\text {foul }}$ : thermal resistance of fouling $\left(\mathrm{m}^{2} \mathrm{~K}\right) / \mathrm{W}$

$S$ : corrugations pitch, $\mathrm{m}$

$t_{11}, t_{12}$ : inlet and outlet temperatures of the hot stream, ${ }^{\circ} \mathrm{C}$

$t_{21}, t_{22}$ : inlet and outlet temperatures of the cold stream, ${ }^{\circ} \mathrm{C}$

$\Delta t_{l n}$ : mean logarithmic temperature difference

$U$ : overall heat transfer coefficient, $\mathrm{W} /\left(\mathrm{m}^{2} \mathrm{~K}\right)$

$w$ : stream velocity in channel, $\mathrm{m} / \mathrm{s}$

$W$ : width of the channel, $\mathrm{m}$

Numbers

$N u$ : Nusselt number; $N u=h \cdot d_{e} / \lambda$

Pr: Prandtl number

$R e$ : Reynolds number; $R e=w \cdot d_{e} \cdot \rho / \mu$

Greek letters

$\beta$ : the corrugations inclination angle to plate vertical axis

$\delta_{w}$ : wall thickness, $\mathrm{m}$

$\gamma$ : aspect ratio of the corrugation doubled height to pitch; $\gamma=2 \cdot b / S$

$\lambda$ : thermal conductivity of the stream, $\mathrm{W} /(\mathrm{m} \mathrm{K})$

$\lambda_{w}$ : thermal conductivity of the wall, $\mathrm{W} /\left(\mathrm{m}{ }^{\circ} \mathrm{C}\right)$

$\mu$ : the dynamic viscosity, Pa s

$\rho$ : fluid density, $\mathrm{kg} / \mathrm{m}^{3}$

$\psi$ : the share of pressure loss due to friction on the wall in total loss of pressure

$\zeta$ : friction factor accounting for total pressure losses in channel

$\zeta_{D Z}$ : the coefficient of local hydraulic resistance in distribution zones

Subscripts

1: hot stream

2: cold stream

w: wall 